\title{
Cotidiano escolar: algumas reflexões sobre a prática do estágio na formação do professor de geografia
}

School dayly life: some reflections about the internship practice in the formation of the geography teacher

\author{
Felipe Moretto Moura' ; Sandra de Castro de Azevedo"
}

\section{RESUMO}

O presente artigo traz reflexões a partir da prática de estágio que é uma atividade essencial para a formação do professor pois possibilita uma inserção no seu campo de trabalho e amplia as possibilidades de pesquisas na área da educação e ensino de geografia. O estágio em questão foi realizado nas aulas de geografia no ensino fundamental II e teve o foco nos marcos legais e nas políticas curriculares e seus desdobramentos no âmbito escolar através do ciclo de políticas de Ball e Bowe. Além das questões políticas este artigo traz reflexões sobre os obstáculos presentes na prática docente e suas problemáticas, como as avaliações externas, o uso do livro didático e a exclusão na escola. Por fim, apresenta as ressignificações do contexto escolar com pouco caráter transformador, legitimando a escola no contexto da qual foi formulada.

Palavras-chave: Geografia; Currículo; Inclusão

\begin{abstract}
This article brings some reflexions from internship practice, which is fundamental to faculty formation because it allows an insertion in your field of work and expands the possibilities of research in the area of education and geography teaching. The internship was carried out in geography classes in elementary school II with special focus in legal landmarks and political curricular and their impact into school setting through the policy cycle from Ball e Bowe. In addition to political issues, this article reflects on the obstacles present in teaching practice and its problems like external evaluations, the use of the didactic and school exclusion. Finally presents empty resignifications the school context lacking transformer aspect, legitimizing the school context of which it was formulated.
\end{abstract}

Keywords: Geography; Curriculum; Inclusion 


\section{INTRODUÇÃO}

Durante o processo de formação de professores de geografia, identificou-se a necessidade de compreender qual é a participação das políticas educacionais no processo de preparação dos futuros professores para uma prática educativa transformadora.

Este artigo tem como objetivo constatar e analisar como as políticas públicas educacionais influenciam diretamente o cotidiano escolar. O estágio supervisionado, instrumento essencial para a formação docente, foi o meio utilizado para a inserção na escola, com objetivo de observar como as políticas educacionais curriculares de geografia e as políticas de organização educacional, estão presentes no cotidiano escolar.

As políticas estão sempre permeadas por diversas intencionalidades que se materializam no cotidiano e que interferem diretamente em nossas práticas socioespaciais. Neste artigo daremos ênfase em como as políticas influenciam as práticas socioespaciais escolares de alunos e professores e quais são as consequências para ambos. Para compreender as práticas socioespaciais é importante considerar o macro e o micro, neste caso o macro corresponde às políticas públicas federais e estaduais e o micro ao espaço da escola. O laboratório desta pesquisa foi uma escola estadual da rede mineira de educação. Essa escola estadual que foi campo de estágio atua nas categorias de ensino fundamental (anos finais) e médio e conta com uma estrutura precária e antiga, o estágio foi realizado no primeiro semestre do ano de 2017, vinculado a disciplina de Laboratório de Ensino de Geografia II do sexto período do curso de Geografia Licenciatura, com uma carga horária de 60 horas de observação e regência na escola, apesar da escola receber diversos estagiários as atividades de cada estagiário aconteceu de forma individual.

O presente artigo se divide em quatro pontos principais: o primeiro trata das políticas educacionais brasileiras em um pequeno panorama de sua implementação para assim chegar à segunda parte, a forma como as políticas se inserem no 
cotidiano escolar, suas consequências e ressignificação. A terceira e a quarta etapas trazem a articulação das observações realizadas na prática de estágio ao identificar fenômenos da escola como privações didáticas, relação docente-currículo, e a exclusão/inclusão escolar.

\section{AS POLÍTICAS EDUCACIONAIS BRASILEIRAS E O NEOLIBERALISMO}

Neste tópico abordaremos de forma sucinta um panorama geral sobre as políticas educacionais e seus marcos normativos, para poder compreender então como se dá sua aplicabilidade dentro do espaço escolar, pensando também sob quais influências foram geradas.

Muitas análises feitas sobre a educação, a escola e o ensino não analisam as políticas que os norteiam, neste artigo ressalta-se que, antes de tudo, pensar o ensino sem pensar as leis que o regem seria um equívoco, assim como afirma Jefferson Mainardes:

Argumentar-se-á que a abordagem do ciclo de políticas constitui-se num referencial analítico útil a análise de programas e políticas educacionais e que essa abordagem permite a análise crítica da trajetória de programas e políticas educacionais desde sua formulação inicial até a sua implementação no contexto da prática e seus efeitos (MAINARDES, 2006, p. 48).

Dentro deste contexto o estágio passa a ser um momento importante para se entender como as políticas públicas educacionais estão presentes na escola, pois pensar a formação de professores sem pensar as políticas públicas educacionais seria, portanto, uma reprodução da prática alienante docente, o que em consequência levaria à alienação dos estudantes.

Sobre as políticas públicas educacionais ABDI, 2012 trata da origem deste processo expondo as influências nos países "em desenvolvimento" sob a ótica de estruturação de políticas educacionais dentro da orientação neoliberal, por meio 
dos Structural Adjustment Programs (SAPS), ou seja, do Banco Mundial (BM) e do Fundo Monetário Internacional (FMI).

Aqui, a política educacional, que deveria discutir o modelo e o projeto de gestão educacional, bem como a distribuição dos recursos de ensino e aprendizagem, foi completamente exposta às políticas econômicas e neoliberais, que, ideologicamente e menos pragmaticamente, avançam o centralismo global das forças de mercado e do Estado Mínimo (MAINARDES, 2006, p. 51).

A partir destes esclarecimentos, das orientações sob as quais as políticas se constroem, será apresentada breve análise das leis que foram foco desta pesquisa, são leis de políticas federais e estaduais que tratam a organização do currículo escolar e a organização das escolas propriamente ditas. Os documentos analisados foram a Lei de Diretrizes e Bases da Educação Nacional (LDB) os Parâmetros Curriculares Nacionais (PCNs), a Base Nacional Comum Curricular (BNCC), o Conteúdo Básico Comum Mineiro (CBC), e a Resolução SEE/MG n. 2.197/2012. A articulação destas leis e suas ressignificações na escola interferem diretamente nas práticas socioespaciais que ocorrem no cotidiano escolar e também na concepção de geografia escolar que os alunos vão desenvolver.

Dentre as políticas educacionais, ressaltamos a Lei de Diretrizes e Bases da Educação Nacional (LDB), Lei 9.394 de 20 de dezembro de 1996, que é o marco fundamental na educação brasileira, abrange todos os níveis, etapas e modalidades de ensino, apesar de datar de 1996 a LDB sofreu várias alterações ao longo do tempo, sendo as mais recentes em 2017. A LDB pode ser entendida como um marco das políticas neoliberais no país, mas este fato não desvaloriza importantes avanços que essa lei trouxe, como a obrigatoriedade do ensino como dever do Estado, incumbências das escolas, normas de gestão, seguridade do ensino público, assim como referência de como deve ser o currículo. 
Ao analisar a escola, campo de estágio e laboratório desta pesquisa, foi possível constatar que a LDB possibilitou sim acesso à educação, mas se faz necessário questionar em quais condições, o que será feito ao longo deste texto.

No Brasil, sobretudo após a promulgação da Lei de Diretrizes e Bases da Educação Nacional - LDB, em 1996, houve uma expansão no acesso à educação escolar nunca antes vista em outro momento histórico. Ocorre que tanto a LDB quanto a Constituição Federal e o Estatuto da Criança e do Adolescente primaram pela expansão da escolarização, não garantindo condições mínimas de qualidade, ou seja, trata-se de uma educação voltada apenas para a instrumentalização do trabalhador e não para garantir que ele se aproprie dos conhecimentos historicamente produzidos pela humanidade e seja formado integralmente (BASSO; BEZERRA NETO, 2014, p. 5).

Seguindo o caminho das políticas educacionais de cunho neoliberal, no final da década de 1990 foram lançados os PCNs, com o objetivo, pelo menos no discurso, de auxiliar os professores a tratar os conteúdos programáticos. Os PCNs de Geografia do ensino fundamental II foram alvos de várias pesquisas, as quais em seus resultados destacaram como ponto positivo deste documento a inserção dos conceitos geográficos, da dialética e da fenomenologia na Geografia Escolar, e destacaram como negativa a tentativa de homogeneizar os currículos, com o discurso de se levar o mesmo nível de aprendizado a todos os alunos, independente da região e contexto em que vivem.

É importante pensar aqui que este documento dificulta a aplicação da parte diversificada, prevista na LDB. Pensando o número de aulas semanais de Geografia, a diversidade de conteúdos, o tempo produtivista das aulas e as temáticas transversais curriculares teremos um cenário em que o professor terá dificuldade em tratar todas as temáticas e de organizar seu tempo para que consiga valorizar a parte diversificada. 
No cotidiano escolar, no campo de estágio, os professores relataram não seguirem os PCNs, mas seguem em sua maioria livros aprovados pelo Programa Nacional do Livro Didático (PNLD), que foi pautado nos PCNs, enquanto este era a norma que orientava este processo, desta forma direta ou indiretamente o professor está colocando em prática a política curricular federal.

Com objetivo de ampliar o controle sobre o conteúdo trabalhado na escola, o Ministério da Educação publicou a Resolução CNE/CP N²2, de 22 de dezembro de 2017 para instituir e orientar a implementação da Base Nacional Comum Curricular da educação infantil e do ensino fundamental, organizada claramente para ampliar o controle, visando a homogeneização dos conteúdos, os quais neste documento são tratados como "conhecimento e competências" a serem desenvolvidas na educação básica. Apresentando os conteúdos de forma mais específica e com menos flexibilidade, por exemplo, os PCNs traziam propostas de eixos temáticos divididos em dois ciclos e os professores escolhiam o que trabalhar em cada ciclo, já a BNCC apresenta uma ênfase ao desenvolvimento do pensamento espacial geográfico do aluno, que é um importante elemento para entender a geografia como um instrumento que possibilita a compreensão da realidade, no entanto determina os conteúdos e as competências para cada ano do ensino fundamental, e no caso da disciplina de Geografia os conteúdos foram reduzidos e fragmentados, dificultando assim uma Geografia Escolar transformadora e diminuindo a autonomia docente, tão ameaçada por vários movimentos na sociedade. É importante destacar que na época da implementação dos PCNs, o documento sofreu com fortes críticas dos especialistas da academia e dos professores da educação básica, atualmente as críticas são destinadas a BNCC.

De acordo com a LDB, cada estado pode implantar um currículo oficial “Art. 10. Os Estados incumbir-se-ão de: III - elaborar e executar políticas e planos educacionais, em consonância com as diretrizes e planos nacionais de educação, integrando e coordenando as suas ações e as dos seus Municípios;" (BRASIL, 2013). O Estado de Minas Gerais implantou o Currículo Básico Comum, este vem tratar dos 
conteúdos como habilidades e competências técnicas, afirmando basear-se nos PCN, já que não fere uma lei federal. O estágio ocorreu em uma escola estadual de Minas Gerais, fato que possibilitou o contato com o CBC na prática do professor. Este documento trabalha as temáticas geográficas como meras competências técnicas, deixa evidente o caráter tecnicista que se busca com essa educação, voltamos então ao caráter de formulação destes instrumentos, permeados pela lógica liberal, que trazem sentidos contrários à compreensão e leitura de mundo crítica que se pretende através da disciplina de Geografia.

A expansão educacional sob a perspectiva do neoliberalismo tem disseminado a formação mínima, que instrumentaliza a maior parte da classe trabalhadora, e especializa parte dela para suprir as necessidades produtivas, e paralelamente a esta realidade existe a educação da e para a elite que, abrigada no sistema privado de ensino, não abre mão dos conteúdos e das "cargas pesadas" de conhecimento (BASSO; BEZERRA NETO, 2014, p. 7).

Também fica evidente aqui que a discussão de currículo está, na maioria das vezes, vinculada a outras políticas educacionais, como as avaliações externas. Ou seja, o ponto de partida não é o cotidiano escolar, e o objetivo também não é possibilitar aos alunos práticas socioespaciais conscientes e transformadoras, mas sim as metas que devem ser atingidas, enquadrando a educação à competição de mercado, deixando de lado sua função social.

Por fim, chegamos então à Resolução SEE/MG n. 2.197/12, que prevê a organização e funcionamento das escolas do estado de Minas Gerais, tal resolução aborda disposições político-pedagógicas, etapas e modalidades da educação básica, especial, profissional, indígena, quilombola, do campo e EJA.

A resolução apresenta um caráter controlador, prevê a supervisão das escolas, remanejamento de alunos, organização dos dias letivos, como devem ser feitos e seguidos, sempre sob fiscalização das chamadas superintendências de ensino por meio de seus inspetores e reafirma provas de avaliação de desempenho anuais, 
reflexo da forma como a educação tem sido pensada por quem a organiza, com princípios de uma produção quantitativa e mensurável ao invés da capacidade reflexiva.

Por meio da análise dessas políticas educacionais fica evidente que existe uma governança educacional que se preocupa muito com uma educação norteada por índices que definem a educação por meio de competências e habilidades, tornando o ensino mais técnico e ampliando o controle sobre a educação, limitando assim a possibilidade de criação e de transformação pela educação.

\section{A INFLUÊNCIA DAS POLÍTICAS PÚBLICAS NO COTIDIANO ESCOLAR}

É necessário um olhar mais aprofundado sobre a educação, e claro, o conhecimento das leis e currículos que a estruturam para saber quais são suas influências no cotidiano escolar, a partir da observação e análise entender como estas se dão de fato, Mainardes refletindo sobre o ciclo de política de Ball e Bowe afirma que,

a "política proposta", referia-se à política oficial, relacionada com as intenções não somente do governo de seus assessores, departamentos educacionais e burocratas encarregados de "implementar" políticas, mas também intenções das escolas, autoridades locais e outras arenas onde as políticas emergem. A "política de fato" constituía-se pelos textos políticos e textos legislativos que dão forma à política proposta e são as bases iniciais para que as políticas sejam colocadas em prática. Por último, a "política em uso" referia-se aos discursos e às práticas institucionais que emergem do processo de implementação das políticas pelos profissionais que atuam no nível da prática. (MAINARDES 2006, p.49):

A partir daqui há uma tentativa de associar a "política em uso" com as práticas observadas no ambiente escolar, trazendo à luz alguns casos vivenciados e observados durante o período de estágio supervisionado, para aproximação da teoria e prática que aparentemente são tão distantes. As exemplificações se 
organizaram da seguinte forma: 3.1 Avaliações externas; 3.2 As aulas de geografia, o currículo e a formação inicial e continuada do professor; 3.3 A lógica da exclusão na inclusão na escola.

\subsection{Avaliações externas}

Nesta concepção de educação a avaliação é um importante instrumento para criar índices educacionais e propor metas para sistema, aliás, as avaliações acabam sendo o ponto de partida de grande parte das políticas curriculares.

Ressalta-se que as políticas avaliativas tomaram grande corpo e mesmo nos governos seguintes (Luiz Inácio Lula da Silva, 20032010 e Dilma Roussef, 2011-2016), com orientações políticoideológicos diferentes dos governos anteriores, houve investimento e aperfeiçoamento das estratégias avaliativas enquanto mecanismos de controle. Essas políticas trazem à tona a ideia de um Estado Avaliador, que possibilita a descentralização das práticas pedagógicas, mas, no final do processo, exige que todos passem pelos mesmos critérios em exames e testes unificados (MOCARZEL; ROJAS; PIMENTA, 2018, p. 165).

No caso do estado de Minas Gerais foi criado no ano de 2000 o Sistema Mineiro de Avaliação da Educação Pública (SIMAVE). Segundo o próprio site da instituição "O Sistema de Monitoramento Escolar é um sistema online que reúne informações e indicadores educacionais de toda a rede de ensino para o uso de diferentes públicos como gestores, técnicos da secretaria, diretores escolares e professores". Como avaliação externa o SIMAVE possui o Programa de Avaliação da Rede Pública de Educação Básica (PROEB) que desde 2000 avalia os estudantes do $5^{\circ}$ e $9^{\circ}$ anos do Ensino Fundamental e do $3^{\circ}$ ano do Ensino Médio das escolas municipais e estaduais de Minas Gerais. Até o momento as avaliações ocorreram nos anos de 2000, 2003 e de 2006 a 2014. Outro programa que compõe o SIMAVE é o Programa de Avaliação da Alfabetização (PROALFA) que desde 2006 avalia alunos 
do $3^{\circ}$ ano do ensino fundamental. Na Resolução SEE n. 2197 de 2012 o SIMAVE foi incluído, ressaltando a influência deste na escola, como indicado no

Art. 71 A análise dos resultados da avaliação interna da aprendizagem realizada pela Escola e os resultados do Sistema Mineiro de Avaliação da Educação Pública - SIMAVE-, constituído pelo Programa de Avaliação da Rede Pública de Educação Básica - PROEB -, pelo Programa de Avaliação da Alfabetização - PROALFA - e pelo Programa de Avaliação da Aprendizagem Escolar - PAAE - devem ser considerados para elaboração, anualmente, pela Escola, do Plano de Intervenção Pedagógica (PIP).

Os programas contemplam provas que são realizadas pelos alunos, diante desta avaliação obtém-se um ranking de avaliação das escolas, o que leva a um consequente status de escolas "boas" e "ruins". Os resultados das provas são anuais, diante dos resultados, são destinadas verbas às escolas, consequentemente as de melhor resultado passam a receber maior apoio financeiro que as outras escolas.

Os resultados das políticas avaliativas produzem o que convencionou-se chamar de efeitos de responsabilização ou accountability (BALL 2005; HYPOLITO, 2010). Trata-se de um sistema de prestação de contas, que direciona à escola, aos gestores e, principalmente, aos professores, a responsabilidade exclusiva pelo sucesso ou pelo fracasso dos alunos. Esse modelo, baseado na lógica do mérito, acaba por comprometer o trabalho docente, na medida em que os objetivos passam a ser os resultados e não a qualidade dos processos. Isso impacta nas políticas de valorização, que passaram a ter como medidas os resultados em testes em larga escala e índices impostos pelo governo (MOCARZEL; ROJAS; PIMENTA, 2018, p. 165).

Essa relação do resultado da avaliação com a verba que a escola pode receber é presente no cotidiano escolar, a ponto de a escola criar estratégias para que os 
alunos tenham compromisso com a realização da prova, transferindo a responsabilidade das condições da escola para os alunos.

Durante o período de realização do estágio, observou-se uma conversa do professor supervisor com os alunos sobre a aplicação da avaliação SIMAVE em que o professor afirmava o caráter negativo deste tipo de avaliação e como isso reforça estereótipos negativos de escolas com baixo rendimento. Porém, pediu aos alunos que se esforçassem na avaliação, pois também poderia ser benéfico à escola em que estudam para atrair recursos do estado diante de um resultado positivo.

O próprio documento CBC-MG reafirma este caráter ao justificar sua importância.

A importância dos CBCs justifica tomá-los como base para a elaboração da avaliação anual do programa de avaliação da educação básica (PROEB) e para o programa de avaliação de aprendizagem escolar (PAAE) e para o estabelecimento de um plano de metas para cada escola (MINAS GERAIS, CBC, 2008, p. 1).

Assim torna evidentes as reais intenções de uma proposta de educação pautada na produtividade, a ausência de preocupação com o aprendizado colocando as escolas em disputa em um ranking escolar, gerando a competição mais perversa entre os corpos escolares, cada vez mais excluindo e segregando aqueles de "baixo rendimento". O professor afirmou ainda que o governo do estado envia placas para as escolas para serem expostas nas fachadas, e relatou que enquanto esteve frente à direção em anos anteriores descumpriu ordens de expor a placa. Essa postura do professor revela a forma dialética de sua análise das políticas educacionais.

Um ponto que enfatizaremos aqui é a organização dos conteúdos de geografia trabalhados em sala, que passa então a se estruturar em função de avaliações como esta, em uma tentativa "desesperada" da escola em obter recursos para melhora da estrutura de seu espaço, além disso, negligencia o sentido da educação enquanto ensino-aprendizagem e formação dos indivíduos, descaracterizando o 
verdadeiro sentido da Geografia Escolar, passando a ser pensada exclusivamente na obtenção de metas, neste caso o resultado da avaliação SIMAVE.

Essa proposta de educação pautada em metas é defendida por setores que apresentam interesse no resultado do sistema educacional.

A partir do argumento da busca pela "qualidade" na educação brasileira, o setor empresarial e industrial se torna cada vez mais presente, travestindo-se em movimentos em prol da educação. Promovem articulações de peso e acabam por estar presentes nas discussões nacionais, construindo sentidos e difundindo hegemonias de parâmetros globalizantes e mercadológicos (LIMAVERDE, 2015, p. 86).

Aqui é importante trazer reflexão, pensando em uma educação democrática e participativa, sobre os debates que devem ser propostos pela escola para discussão com a comunidade, pais, familiares, alunos e escola, para se pensar essas avaliações, refletir sobre a forma como impactam as escolas, se devem ser boicotadas ou não, se há nas avaliações algo positivo, se o conteúdo será ministrado em função das avaliações como determina a resolução n. 2.197/12, ou seja, informar a população para então se discutir o que deve ser feito.

Não se deve esquecer que a escola está posta na sociedade para atender suas demandas, e não omitir acontecimentos que impactam seu funcionamento e refletem no cotidiano e formação dos indivíduos.

Abdi (2012) afirma que deveria ser claro o modo como o trio neoliberalismo, globalização e políticas públicas educacionais prescritas estão afetando a vida das pessoas em quase todos os cantos do mundo. Nesta pesquisa foi possível perceber que a pressão e o controle que as políticas públicas educacionais levam para dentro da escola, podem reproduzir no ambiente escolar o medo e a obediência, uma vez que os gestores e os professores são atingidos diretamente por essas políticas e isso impacta diretamente nas suas atividades diárias na escola. Em Minas Gerais, para completar o controle, a gestão da escola tem de manter atualizados todos os 
meses até o quinto dia útil os dados da escola no Sistema Mineiro de Administração Escolar (SIMADE), implementado pela resolução da SEE n. 1.180, de 28 de agosto de 2008, e a direção escolar que não cumprir estará sujeita a sanções administrativas, ou seja, apesar de entendermos que a elaboração e organização de dados são importantes para o planejamento escolar, o que presenciamos na escola é uma pesada burocratização e controle, deixando pouco espaço para o fazer pedagógico.

\subsection{As aulas de geografia, o currículo e a formação inicial e continuada do professor}

A vivência de estágio nas aulas de geografia, com participação e a observação das práticas do professor de geografia supervisor do estágio, as conversas durante todo o período, norteadas pela teoria, geraram inquietações e questionamentos, os quais são essenciais no processo de formação dos estagiários.

Buscando entender a relação do professor com as políticas educacionais curriculares, questionamos o professor quanto aos PCNs de Geografia, à forma como ele estrutura as aulas a serem ministradas, como organiza, critérios avaliativos, como atende ou não às demandas das políticas públicas, enfim, como orienta sua prática a partir dos parâmetros legais.

Diante do questionamento o professor de geografia respondeu:

“... eu nunca li, não quero ler e tenho é raiva faz 35 anos que dou aula e nunca precisei disso..."

O professor afirmou ainda que o currículo é controlador e desvaloriza o profissional, e que sua experiência prática tem mais valor que tais documentos que são "bobagens”, e disse ainda: “... eu me oriento é por isso aqui...", apontando para o material que selecionou e utiliza como base para suas aulas.

É importante refletir alguns pontos sobre as afirmações, o professor possui uma formação que antecede os PCNs, desta forma levantamos a hipótese de que o mesmo não teve formação continuada adequada para apresentá-lo ao documento, talvez esse tenha sido um dos maiores obstáculos para um maior uso dos PCNs, a 
dificuldade de fazer o mesmo chegar aos professores de geografia que estão na ativa. No entanto na fala também é possível perceber um posicionamento político do professor que entende que essas políticas curriculares não dão voz aos professores e ameaçam sua autonomia.

As avaliações e o que avaliam e privilegiam passaram a ser currículo oficial imposto às escolas. Por sua vez o caráter centralizado das avaliações tira do docente o direito a serem autores, sujeitos da avaliação do seu trabalho. A priorização imposta de apenas determinados conteúdos para a avaliação reforça hierarquias de conhecimentos e consequentemente de coletivos docentes (ARROYO, 2016, p. 35).

Ainda que o professor de geografia não acredite no sistema como posto é a partir do seu conhecimento que se pode ressignificar ou ainda subverter um sistema.

De acordo com Ball e Bowe (Bowe et al., 1992), o contexto da prática é onde a política está sujeita à interpretação e recriação e onde a política produz efeitos e conseqüências que podem representar mudanças e transformações significativas na política original. Para estes autores, o ponto-chave é que as políticas não são simplesmente "implementadas" dentro desta arena (contexto da prática), mas estão sujeitas à interpretação e, então, a serem "recriadas" (MAINARDES, 2006, p. 53).

O professor de geografia afirma não utilizar os PCNs, fato que nos leva a indagar: a quem ele segue? Ou ainda, a quem o professor acha que está deixando de seguir?

Nesse quadro, nos debatemos na história tensa de conformação de autoidentidades docentes. Se pouco importa educar a que ficam reduzidas nossa identidade e função dos currículos, das escolas e do conhecimento? Estamos em tempos em que essa indefinição e essa lacuna identitária ficam mais expostas diante dos educandos (ARROYO, 2016, p. 25). 
O professor supervisor de estágio afirmou não utilizar o livro do PNLD e também afirmou não seguir as orientações dos PCNs, mostrando desta forma que é contrário a essas políticas públicas educacionais, no entanto o professor conduz suas aulas com uma postura crítica, levando o aluno a refletir sobre sua realidade por meio dos conteúdos de geografia, com base nessas observações é possível entender que o professor entende a função social da sua profissão e resiste à alienação.

No trabalho alienado, "a vida mesma aparece só como meio de vida" (Marx 1984, p. 156 - grifos no original), sendo entendido, assim, como meio de existência, como uma aparente atividade, como exterior ao trabalhador e não como ato que desenvolve novas capacidades e cria novas necessidades, não como essência humana no sentido da realização das potencialidades alcançadas pelo gênero humano. Para Heller (1992, p. 38) "existe alienação quando ocorre um abismo (...) entre a produção humano-genérica e a participação consciente do indivíduo nessa produção" (BASSO, 1998, p. s/n).

Durante o período de vivência do estágio, constatou-se que, apesar de todo avanço tecnológico, facilidade de acesso à informação, as crianças e jovens, que frequentam a escola que foi campo de estágio, ainda não têm sua formação tão ampla para a tomada de materiais como referência para sua formação, logo, o caderno torna-se o referencial de estudo para a aprendizagem destes alunos, fato esse muito importante e que nos leva ainda a mais uma constatação, o caderno traduz a prática do professor, é através dele que o aluno se apropria dos conteúdos, e se pode observar também a ressignificação que o professor dá aos conteúdos do material que utiliza.

[...] parte do conceito de recontextualização, já que as definições curriculares, como produto social discursiva, representam a eleição de saberes, conceitos e práticas históricas tornadas conteúdos para o desenvolvimento da educação escolar, o que esclarece elementos de ordem 
sociológica (LOPES, 2007). Essa abordagem permite a compreensão do papel, do poder e da ideologia dos agentes recontextualizadores que escrevem e legitimam os currículos, sejam eles o Estado, a autoria dos livros didáticos, os próprios professores etc. (SANTANA FILHO, 2010, p. 172).

Ainda tratando da utilização dos materiais didáticos, essa escolha do professor em não se utilizar dos livros didáticos oferecidos pela escola implica em algumas problemáticas, temos como principais, a privação didática de acesso ao livro didático de geografia distribuído gratuitamente pelo Estado, além do desperdício do dinheiro público e a tomada do livro como uma determinante, e não uma ferramenta.

A privação do acesso ao livro aqui é tomada com certo foco, como discutido acima, o livro é ferramenta fundamental ao aluno enquanto apoio pedagógico de orientação, contextualização, familiarização dos conteúdos e instrumentos didáticos de geografia como mapas e tabelas.

O professor ao não se utilizar do livro não dá ao aluno esse acesso, ainda que se utilize de mapas na sala e outros materiais de apoio, e está restringindo o contato individual com este material, que proporciona familiaridade, facilita o entendimento, instiga a curiosidade e a leitura, possibilita o contato com diversas fontes cartográficas, imagens e diferentes gêneros textuais. Não usar o livro como apoio nas aulas, ficando na dependência, principalmente do caderno, pode trazer defasagem no aprendizado, como foi possível observar durante o período estagiado, além de gerar dificuldades de interpretação por parte dos alunos ao se depararem com o livro didático de geografia, provável reflexo desta prática.

A distribuição dos livros didáticos acontece a cada três anos com direito de seleção do livro por parte do professor, o que é uma política de alto custo ao Estado. Pensar então que estes livros são distribuídos para ficarem "pegando poeira" na biblioteca da escola ou para ficarem nas casas dos alunos sem uso é algo muito preocupante, o que nos leva ao último tópico da discussão que é a tomada do livro didático como um dogma. 
Uma vez que o professor não utiliza do livro disponível porque acha "ruim", ou o julga inadequado, é porque toma os conteúdos do livro como verdades absolutas, o fato de o livro não ser suficiente aos critérios do professor, não significa que ele não possa usá-lo, abordando o mesmo conteúdo de outros modos, contradizendo e evidenciando possíveis erros, desmistificando o caráter do livro como absoluto em sala de aula, e promovendo o contato do aluno com diferentes materiais assim como apontado pela própria política, “Neste contexto que se insere o livro didático[...], constituindo-se como mais uma ferramenta de apoio no desenvolvimento do processo educativo, com vista a assegurar a articulação das dimensões da ciência, cultura, trabalho e tecnologia no currículo..."(BRASIL, 2018, p. 16).

Outra hipótese levantada é de que o professor tendo de seguir o CBC, conforme a Resolução SEE/MG n. 2197 afirma no “Art. 59 Na organização curricular do ensino fundamental e do ensino médio deve ser observado o conjunto de Conteúdos Básicos Comuns (CBC) a serem ensinados, obrigatoriamente, por todas as unidades escolares da rede estadual de ensino" (grifo nosso), encontra dificuldade no uso do livro didático que segue os princípios dos PCNs, que divergem dos princípios do CBC, apesar do CBC afirmar em seu documento que segue os princípios dos PCNs. Temos aqui a tensão entre duas políticas de esferas diferentes que geraram dificuldades para o trabalho do professor.

Arroyo ainda afirma.

Até quando os currículos de licenciatura continuarão ignorando essas tensões na configuração das novas identidades profissionais que acontecem nas salas de aula? É lamentável que os gestores de políticas educativas e curriculares ignorem essas tensões que se dão nas salas de aula (ARROYO, 2016, p. 30).

Segundo Mainardes (2006) os professores exercem um papel ativo no processo de reinterpretação das políticas educacionais e, desta forma, o que eles 
pensam e no que acreditam têm implicações para o processo de implementação das políticas, ou ao menos deveriam exercer esse papel.

\subsection{A lógica da exclusão na inclusão na escola}

Chegamos aqui ao último ponto a ser destacado dentre as observações realizadas no período de estágio, considerado como a mais preocupante dentre as destacadas, a lógica da exclusão das escolas públicas, que foi observado nas aulas de geografia, mas que não se limitam a ela. E que afligem os profissionais da educação.

O Ensino Fundamental deve promover um trabalho educativo de inclusão que reconheça e valorize as experiências e habilidades individuais do aluno, atendendo às suas diferenças e necessidades específicas, possibilitando, assim a construção de uma cultura escolar acolhedora, respeitosa e garantidora do direito a uma educação que seja relevante, pertinente e equitativa (BRASIL, 2012, p. 3).

Durante o período do estágio foi possível acompanhar e viver em sala de aula as situações que indicam os obstáculos da educação inclusiva, relataremos alguns casos de alunos que fazem parte de tal lógica, para abordar a questão optamos por utilizar os rótulos que a escola destinou a esses alunos, esses rótulos indicam qual o tratamento que s escola dá para esses alunos. Sobre as classificações dos alunos nas escolas Arroyo (2007, p.790)

As classificações de crianças, adolescentes e jovens se radicalizam nas escolas e na sociedade. As categorias de normal-anormal, de aluno sem problemas ou com problemas que a escola aplicava ao rendimento escolar agora têm como referente sobretudo qualidades morais dos alunos, de suas famílias e de sua origem. Quando se classifica por parâmetros de rendimento intelectual se usa a expressão "alunos com problemas de aprendizagem", "repetentes", mas permanecendo na escola, ainda confiáveis. Quando as 
classificações são por critérios morais se usa a expressão "alunos-problema" porque, quando violentos, logo são estigmatizados, expulsos, segregados do convívio escolar. Desconfiáveis.

Para facilitar a organização do texto identificaremos os alunos conforme os rótulos destinados à eles, pela escola utilizaremos o termo aluno para garantir a não identificação dos alunos, preservando suas identidades: Um aluno do 7 era classificado pela escola como "Aluno Problema" e dois alunos também do 7 eram classificados como "Alunos da professora de apoio", já no $6^{\circ}$ um aluno era classificado como "Preguiçoso" e outro como "Hiperativo". Esses são quatro casos distintos, que sofrem exclusão na escola e da escola, resultado da ausência do que é posto pela legislação.

Trazemos este tópico com a fundamental reflexão de Arroyo (2016) sobre a identidade profissional, expondo o que não deveria acontecer, mas é presente no cotidiano escolar e chamaremos então de lógica da exclusão a ser descrita nos tópicos posteriores.

As tensões identitárias não são apenas entre ensinar ou educar, mas entre as tensas indagações ao nosso ensinar que vem dessas vivências, da infância-adolescência. Ou a percepção que é inseparável ensinar a seres humanos e levar em conta suas formas de viver, mal-viver como humanos. Trazer a função educativa para nossa identidade profissional é uma exigência do olhar sobre os educandos.

Cada dia percebemos com maior clareza que nossa história docente é inseparável da história humana e social dos (as) educandos (as) com que trabalhamos. Nossas sortes estão atreladas. Só nos entenderemos na medida que tentemos enxergá-los e entende-los. "Eu acho que o que eu mudei foi minha relação com o aluno".

São suas formas tão injustas de viver que puxam nossa sensibilidade profissional de educadores(as). Somos suficientemente profissionais para percebermos que os alunos chegam às salas de aula, aos processos de ensinoaprendizagem carregando vidas precárias. São ecos de 
vivências de outros lugares que chegam às salas de aula e nos obrigam a escutá-los, a não abafa-los com nossas lições e nossas didáticas e ameaças de avaliações-reprovações. Novas exigências profissionais que alargam as lutas por direitos. Quando as identidades se alargam, os direitos profissionais têm de ser ampliados (ARROYO, 2016, p. 29).

Primeiro caso, identificado como "Aluno Problema" entre professores e alunos, ou seja, classificação dada pela escola. Foi relatado em conversas que o aluno vem de família desestruturada e possui problemas psicológicos, toma remédios controlados para conter sua hiperatividade. Pelo que pudemos observar, o aluno tem um tom de voz alto, mas não gera grandes transtornos em sala de aula, os professores se incomodam mais com sua fala do que qualquer outra atitude.

A relação existente entre educação e diversidade coloca-nos diante do seguinte desafio: o que entendemos por diversidade? Que diversidade pretendemos esteja contemplada no currículo das escolas e nas políticas de currículo? Para responder a essas questões, fazem-se necessários alguns esclarecimentos e posicionamentos sobre o que entendemos por diversidade e currículo.

Seria muito mais simples dizer que o substantivo diversidade significa variedade, diferença e multiplicidade. Mas essas três qualidades não se constroem no vazio e nem se limitam a ser nomes abstratos. Elas se constroem no contexto social e, sendo assim, a diversidade pode ser entendida como um fenômeno que atravessa o tempo e o espaço e se torna uma questão cada vez mais séria quanto mais complexas vão se tornando as sociedades (GOMES, 2007, 19).

O "Aluno Problema" é tratado de forma rude pelos agentes escolares, inclusive por professore, é mantido constantemente em suspensão, os próprios colegas afirmam que o aluno vai para a escola um dia, e passa dois ou três em casa. Foi possível observar que o aluno mesmo que suspenso ia até a porta da escola no horário de entrada, como não podia entrar, ficava provavelmente na rua. 
Por fim acreditamos que o aluno abandonou a escola, durante o período de estágio, ele parou de ir às aulas, a ausência do garoto não causou estranhamento a ninguém, aparentemente a escola "se livrou do problema". É importante salientar que os profissionais que atuam nessa escola campo de estágio, não estão satisfeitos com essa situação, mas as condições que são colocadas pelo sistema, acabam contribuindo para esse triste resultado.

"Alunos da professora de apoio", os dois alunos do sétimo ano são deficientes intelectuais, e uma por sua vez também é cadeirante, os dois alunos são acompanhadas por uma "professora de apoio", esse termo é definido de acordo com o Art. 58. Da LDB que no inciso “Haverá, quando necessário, serviços de apoio especializado, na escola regular, para atender às peculiaridades da clientela de educação especial".

Durante o estágio, foi observado que o papel desta professora em sala é única e exclusivamente de copiar os conteúdos no caderno dos dois alunos, uma vez que os dois dentro de suas diferentes limitações brincam o tempo todo em sala.

Pude observar que pela presença dos alunos o professor aplica menos conteúdos para toda a sala, o que torna presente mais uma exclusão, não é cobrado destes alunos nenhum tipo de atividade ou prática diferenciada, na realidade, nada é cobrado, apenas da professora de apoio que copie os exercícios em seus cadernos, como se esta fosse a aluna, e assim, estes alunos continuam "progredindo" nos anos escolares.

No caso dos alunos com necessidades especiais a lei é aplicada como prevista no texto, mas na prática não apresenta um resultado positivo, entende-se que na lei em uso faltou maior organização e articulação por parte do professor regente e da professora de apoio, mediados pela gestão da escola.

O caso do aluno que é "hiperativo". Aluno extremamente agitado, porém não fala muito, foge dos diálogos com os professores, mas como não fica em sua carteira e constantemente quer brincar com os colegas, frequentemente é mandado para fora da sala de aula. Por vezes em outras salas acompanhando aulas 
era corriqueiro vê-lo "passeando" pela escola, participando da educação física de outras turmas.

Pudemos acompanhar poucas vezes a sala do garoto, porém das aulas acompanhadas ou o aluno já estava para fora da sala ou era mandado para fora por atrapalhar a aula, em outras delas o aluno não estava na escola.

A construção do olhar sobre as pessoas com deficiências ultrapassa as características biológicas. Não será suficiente incluir as crianças com deficiência na escola regular comum se também não realizarmos um processo de reeducação do olhar e das práticas a fim de superar os estereótipos que pairam sobre esses sujeitos, suas histórias, suas potencialidades e vivências. A construção histórica e cultural da deficiência (ou necessidade especial, como ainda nomeiam alguns fóruns), enquanto uma diferença que se faz presente nos mais diversos grupos humanos, é permeada de diversas leituras e interpretações. Muitas delas estão alicerçadas em preconceitos e discriminações denunciados historicamente por aqueles(as) que atuam no campo da Educação Especial e pelos movimentos sociais que lutam pela garantia dos direitos desses sujeitos. Como todo processo de luta pelo direito à diferença, esse também é tenso, marcado por limites e avanços. É nesse campo complexo que se encontram as propostas de educação inclusiva (GOMES, 2007, p. 34).

Por fim o caso do "Preguiçoso". Esse garotinho muito tímido e quieto em sala de aula é tratado como preguiçoso e descompromissado com as tarefas escolares, o aluno chamou a atenção exatamente por quase não falar em sala, não realizar as atividades, nem copiar o que estava posto no quadro. Em uma aproximação com o aluno pude observar seu caderno que não tinha nenhum conteúdo, o que levou a minha primeira preocupação, já que estávamos nos aproximando do fim do ano letivo.

Na realidade, a preocupação da escola deverá ser dar a todos(as) o devido tempo de aprender, conviver, socializar, formar-se, consequentemente, ter como critério na organização do currículo a produção de um tempo escolar acolhedor e 
flexível que se aproxime cada vez mais da dimensão cíclica e complexa das temporalidades humanas. O tempo para aprender não é um tempo curto. E, além disso, a escola não é só um espaço/tempo de aprendizagem. Ela é também um espaço sociocultural e imprime marcas profundas no nosso processo de formação humana. Por isso, a organização escolar não pode ser reduzida a um tempo empobrecido de experiências pedagógicas e de vida (GOMES, 2007, p. 38).

Passamos então a acompanhar o aluno com maior atenção, auxiliando-o na execução das atividades, o aluno apresentou extrema dificuldade de escrita e leitura (o aluno só lia algumas palavras aparentemente), ou seja, a escola a rotulou como preguiçoso, e aparentemente não notou a extrema dificuldade de um aluno que não está devidamente alfabetizada no sexto ano, a classificação do aluno como preguiçoso, acaba dificultando um olhar mais atencioso ao aluno, com objetivo de sanar suas dificuldades ainda no início do ensino fundamental II.

O que podemos observar então dentre esses quatro casos relatados é a perversa lógica excludente que a escola produz a partir do momento em que apresenta dificuldades de atender suas obrigações como previstas na LDB, por exemplo.

Art $2^{\circ}$ A educação, dever da família e do Estado, inspirada nos princípios de liberdade e nos ideais de solidariedade humana, tem por finalidade o pleno desenvolvimento do educando, seu preparo para o exercício da cidadania e sua qualificação para o trabalho (BRASIL, 1996, p. 7).

Limaverde destaca.

Ao mesmo tempo, não podemos nos distanciar de uma reflexão crítica sobre a educação do nosso país. Ainda que a legislação permita uma amplitude significativa de atuação e proatividade por parte dos estabelecimentos de ensino e da própria comunidade de educadores, há uma cultura de restrição onde diferentes dispositivos são culpabilizados (LIMAVERDE, 2015, p. 93). 
Esses são os casos que mais chamaram a atenção, dentre tantos outros que podem ter passado despercebidos em nossa análise. Faz-se necessário refletir sobre essas questões, com a intenção de entender melhor o cotidiano escolar com objetivo de repensar as práticas que prejudicam os alunos, professores e gestores, mesmo que para isso seja necessário rever algumas políticas públicas educacionais.

Essa experiência de estágio que possibilitou essa reflexão teorizada sobre o cotidiano escolar é essencial para a formação de professores de geografia, entender as políticas educacionais e compreender como essas estão presentes na escola, esse processo levam os futuros professores e pensar em como criar estratégias para poder utilizar a geografia escolar na resolução destes problemas e leva o estagiário a compreender de vez que ser professor de geografia é muito mais que trabalhar somente o conteúdo de geografia.

\section{APONTAMENTOS FINAIS}

A vivência do estágio nas aulas de geografia possibilitou a realização da análise da política públicas educacionais, tendo como base teórica o Ciclo de Política de Ball e Bowe, que nos permite entender a política em todas as suas etapas e principalmente como essa pode ser ressignificada em cada escola e materializada no cotidiano escolar.

As políticas curriculares e as políticas de organização educacional são colocas em prática de forma parcial e muitas vezes quando colocadas em prática de forma integral não possibilitam chegar ao resultado esperado, isso porque a escola é muito dinâmica e seu controle total é impossível, fato que consideramos positivo, pois em cada brecha encontrada existe uma possibilidade de luta e transformação. E perceber essas possibilidades já no processo de formação é essencial para garantir uma formação inicial mais consolidada aos professores de geografia.

Por meio deste estágio e da reflexão do mesmo, foi possível perceber que as políticas curriculares podem interferir na dinâmica da escola, uma vez que o projeto 
pedagógico da escola, será influenciado por essas políticas, sejam elas mais voltadas para a questão curricular ou mais voltadas para a organização da instituição.

Como pode ser constatado após a apresentação deste artigo, condições básicas postas pela LDB/96 ainda não estão presentes nas escolas, como respeito pela diversidade e inclusão que são condições que deveriam ser garantidas aos alunos, mas o próprio sistema dificulta essa garantia e a escola acaba sofrendo as consequências deste processo. Ressignificações vazias são produzidas dentro do espaço escolar, pois essa ressiginificação não ocorre de modo transformador, o que inviabiliza a construção de uma escola acolhedora, democrática e que zele pela aprendizagem dos alunos.

Desse modo, observa-se que a escola tem cumprido, e muito bem, seu papel de origem de formação, a partir de um Estado burguês que pensou a "educação" das massas para a produção de mão de obra barata e alienada, neste sentido sim a escola tem cumprido muito bem seu papel, tratando também de excluir aqueles que não estariam aptos a se adaptar ao seguimento de ordens e ritmo produtivista de trabalho, por exemplo.

No entanto não podemos deixar de destacar que existe um descontentamento da escola com essa situação e a gestão e os professores e funcionários, buscam sempre estratégias para tornar a escola mais inclusiva e acolhedora.

\section{REFERÊNCIAS}

ABDI, A. A. Políticas educacionais internacionais em tempos de globalização neoliberal: desafios ao desenvolvimento social. In: GUIMARÃES-IOSIF, Ranilce (Coord.). Política e governança educacional: contradições e desafios na promoção da cidadania. Brasília, DF: Editora Universa, 2012.

ARROYO, MIGUEL GONZÁLEZ. Quando A Violência Infanto-Juvenil Indaga a Pedagogia Educ. Soc., Campinas, vol. 28, n. 100 - Especial, p. 787-807, out. 2007. 
Disponível em: http://www.scielo.br/pdf/es/v28n100/a0828100.pdf. Acesso em 19 fev.2020

ARROYO, Miguel. Currículo, território em disputa. Petrópolis, RJ: Vozes, 2016.

BASSO, Itacy Salgado. Significado e sentido do trabalho docente. Cad.

CEDES [online], Campinas, v. 19, n. 44, p. 19-32, abr 1998. Disponível em: http://www.scielo.br/scielo.php?script=sci_arttext\&pid=S010132621998000100003\&lng=pt\&tlng=pt. Acesso em: 20 set. 2018. http://dx.doi.org/10.1590/S0101-32621998000100003.

BASSO, I. S.; BEZERRA NETO, L. As influências no neoliberalismo na educação brasileira: algumas considerações. Itinerarius Reflectionis, Universidade Federal de Goiás, Jataí (GO), v. 10, n. 1, 2014. Disponível em: https://www.revistas.ufg.br/rir/issue/view/1491/showToc. Acesso em: 20 set. 2018.

BRASIL. Lei 9394/96, de 20 de dezembro de 1996. Lei de Diretrizes e Bases da Educação Nacional. Disponível em: http://www.planalto.gov.br/ccivil_03/LEIS/L9394.htm. Acesso em: 17 fev. 2013.

BRASIL. Secretaria de Educação Fundamental. Parâmetros Curriculares Nacionais: Geografia. Brasília: MEC/SEF, 1997.

BRASIL. Ministério da Educação, Conselho Nacional de Educação e Câmara de Educação Básica. Resolução n 7 de 14 dezembro de 2010. Fixa Diretrizes Curriculares Nacionais para o Ensino Fundamental de 9 (nove) anos. Brasília, 2010. Disponível em: http://portal.mec.gov.br/dmdocuments/rceb007_10.pdf. Acesso em: 07 nov. 2018.

BRASIL. Ministério da Educação. Guia PNLD 2018. Disponível em: https://www.fnde.gov.br/pnld-2018-arte/index.html. Acesso em: 07 nov. 2018.

GOMES, Nilma Lino. Indagações sobre currículo: diversidade e currículo. Brasília, DF: Ministério da Educação, Secretaria de Educação Básica, 2007. 48 p.

LIMAVERDE, Patrícia. Base Nacional Comum: desconstrução de discursos hegemônicos sobre currículo mínimo.Revista Terceiro Incluído, Universidade Federal de Goiás, Goiânia (GO), v. 5, n. 1, p. 78-97, Artigo 84, jan./jun. 2015.

MAINARDES, Jefferson. Abordagem do ciclo de políticas: uma contribuição para a análise de políticas educacionais. Educ. Soc., [online], Campinas, v. 27, n. 94 p. 4769, jan./abr. 2006. Disponível em: http://www.scielo.br/scielo.php?script=sci_arttext\&pid=S0101 73302006000100003\&lng=en\&nrm=iso. Acesso em: 20 set. 2018. 
MINAS GERAIS. Secretaria de Estado de Educação. CBC Geografia - Ensinos

fundamental e médio. Disponível em: http:// www.educacao.mg.gov.br. Acesso em: 18 nov. 2008.

MINAS GERAIS. Secretaria Estadual de Educação. Resolução SEE/MG 2.197, de 26 de outubro de 2012.

MINAS GERAIS. Resolução n 2.197/12. Disponível em:

https://www.mg.gov.br/instituicao_unidade/secretaria-de-estado-de-educacao-see. Acesso em: 07 nov. 2018.

MOCARZEL, M. S. M. V.; ROJAS, A. C.; PIMENTA, M., de F. B. A Reforma do ensino médio: novos desafio para a gestão escolar. Revista online de Política e Gestão Educacional, Araraquara, v. 22, n. 1, p. 159-176, jan. 2018.

SANTANA FILHO, M. M. A educação geográfica escolar: conteúdos e referências docentes. 2010. 420 f. Tese (Doutorado em Geografia) - Programa de Pós Graduação do Departamento de Geografia da Faculdade de Filosofia, Letras e Ciências Humanas, Universidade de São Paulo, São Paulo. 